\title{
Revisiting Reputation: How Past Actions Matter in International Politics
}

\author{
Alex Weisiger and Keren Yarhi-Milo
}

\begin{abstract}
Policy-makers and political scientists have long believed that states must make policy with an eye to maintaining a good reputation, especially a good reputation for resolve. Recent work, however, has argued that reputations for resolve do not form, and hence that past actions do not influence observers' behavior in subsequent interactions. This conclusion is theoretically problematic and unsupported by the evidence offered by reputation critics. In particular, juxtaposing reputation for resolve to power and interests is misleading when past actions influence observers' beliefs about interests, while the common approach of looking at crisis decision making misses the impact of reputation on general deterrence. We thus derive hypotheses about conflict onset from both the arguments of reputation critics and the logic of more standard reputation arguments, which we put to statistical test. We find that past action is closely connected to subsequent dispute initiation and that the effects of reputation generalize beyond the immediate circumstances of the past dispute. Although reputation is not all-important, leaders are well advised to consider the reputational implications of policy decisions in international conflict.
\end{abstract}

Leaders often claim that a reputation for resolve is worth fighting for. President Harry Truman justified intervention in Korea on the grounds that a failure to respond "would be an open invitation to new acts of aggression elsewhere."1 Justifying a firm policy by invoking concerns for the country's reputation may serve as an effective rhetorical tool to garner the public's support. But are leaders right to be concerned about their country's reputation for resolve? Does having a good or a bad reputation for resolve matter in international politics?

Both policy-makers and international relations scholars traditionally have answered both these questions in the affirmative. However, drawing on a surprising dearth of evidence of reputation in the historical record, a growing literature argues both theoretically and empirically that states do not in fact develop reputations for resolution or irresolution. This conclusion suggests that leaders' efforts to build and protect those reputations have been wasted.

We thank David Carter, Avery Goldstein, Michael Horowitz, Robert Jervis, Jack Levy, Ed Mansfield, Jon Pevehouse, Jessica Stanton, and anonymous reviewers for useful comments and conversations. A previous version of this article was prepared for presentation at the 2013 International Studies Association Conference in San Francisco.

1. “Text of Truman's 'Report to Nation' on Korea War," New York Times, 2 September 1950, A4. 
We argue that this conclusion is incorrect: although reputation for resolve may not be as all-important as early deterrence theorists claimed, there are real consequences to appearing resolute or irresolute. Specifically, reputation critics misunderstand the strategic logic of reputation for resolve and hence unintentionally bias their studies against finding reputation for two reasons. First, they juxtapose reputation to power and interests, but the effects of reputation act primarily through estimates of the opponent's interests. Second, they focus their attention on crisis diplomacy, where the effects of reputation are less obvious and harder to observe, rather than on general deterrence. We derive hypotheses from the competing theoretical camps, which we subject to empirical tests.

In brief, we find that leaders are right to be concerned about their country's reputation for resolve. Contrary to the predictions of reputation critics, we find a strong relationship between a country's past action and the probability of a new dispute. These results hold using different measurements, specifications, and robustness checks. This relationship is quite general, holding for both good and bad reputation, for observers as well as participants in a dispute, and through leadership turnover, though the evidence suggests some limitations in generalization across issue areas.

\section{Reputation for Resolve and International Relations Theory}

\section{What Is Reputation for Resolve?}

To examine the relationship between reputation for resolve and the onset of interstate disputes, we need to be clear about how we define "resolve" and "reputation." Following Mercer, we characterize resolve as "the extent to which a state will risk war to achieve its objectives." 2 Resolve in turn depends on one's valuation for the stakes involved and valuation for the cost of fighting. Highly resolved actors are more willing to suffer the costs of fighting to achieve a desirable outcome in the political dispute. Resolve is thus a dispositional characteristic, albeit one that can vary over time or across issues. A state's resolve is private information about its own willingness to risk war, but it is obviously of critical importance to its opponent, whose own demands will depend on its beliefs about the first state's resolution.

Reputation for resolve, then, refers to others' perception of that state's willingness to risk war. Because talk is cheap, this reputation depends primarily on what the state has done in the past. Backing down in one dispute suggests to observers that the state does not care much about the issue in dispute relative to the costs of fighting, and hence that it would be likely to make concessions in similar disputes. A state with a better reputation for resolve will therefore be believed to be more likely to stand firm and, if necessary, fight in response to any particular demand by an opponent. However, saying that a state has a reputation for resolve does not necessarily 
imply that the state will be expected to always fight in any disagreement; one of the benefits of a good reputation is that it should convince the opponent to make more moderate proposals in any disagreement.

\section{Evaluating the Literature on Reputation for Resolve}

The study of reputation in international relations emerged out of the Cold War literature on deterrence, associated in particular with Schelling's argument that failure to respond to Soviet probes around the world would invite further, increasingly aggressive action elsewhere. ${ }^{3}$ From this perspective, if a country consistently keeps its promises and carries out its threats, its commitments will carry weight. But a country with a history of backing down in crises will be seen as irresolute, and its subsequent threats will be doubted. Expecting that future behavior will mimic past behavior, observers are more prone to challenge such a country, expecting their opponent to back down when challenged. At the core of this theory lies the assumption that commitments are interdependent, even across actors, regions, and issue areas: in the strong version, a state's behavior in interactions with country A in a dispute over territory in Asia will influence country B's behavior in a potential regime dispute with that state in Europe. Ever since, scholars have developed theoretical arguments in which reputation and concern for maintaining one's reputation play a central role. ${ }^{4}$

Orthodox reputation theory gained widespread acceptance on the basis of its clear internal logic and strong policy recommendations rather than on the basis of empirical tests. Moreover, the strong interdependence of commitments within the theory rests more on assumption than on theoretical argument. In short, there is nothing in deterrence theory that necessarily implies that lessons from past actions will outweigh issue- and crisis-specific variables in decisions about crisis initiation. ${ }^{5}$

In fact, a series of studies found surprisingly little evidence that policy-makers based their decisions on opponents' past actions. Hopf reports that Soviet leaders did not infer from US actions in peripheral regions anything about likely behavior in Europe or East Asia. ${ }^{6}$ Building on findings in psychology, Mercer argues that leaders attribute decisions to back down in a crisis to situational characteristics of the crisis rather than to any permanent or dispositional feature of the opponent, and hence that reputations for irresolution will not form between adversaries. ${ }^{7}$ Most damningly, in case studies of the European politics in the 1930s and of Soviet-American relations during the Cold War, Press finds no evidence that either

3. See Schelling 1960 and 1966.

4. For prominent recent examples, see Treisman 2004; Wolford 2007; and Sechser 2010.

5. The points in this paragraph are made by Jervis 1979; and Huth 1997, among others.

6. Hopf 1994. See also Snyder and Diesing 1977; and Lebow 1981, for further examples of scholars finding limited evidence of reputation in historical case studies. Orme 1992, by contrast, argues that in several cases Soviet leaders did infer that the United States lacked resolve based on its failure to respond more forcefully in past conflicts.

7. Mercer 1996. He also claims that "victory in war does not guarantee a reputation for resolve-especially among those who are strongly motivated to view a state as irresolute." Ibid., 220. 
Nazi leaders or American policy-makers made predictions about the likely behavior of their opponents based on their record of backing down in previous crises. ${ }^{8}$ Both Mercer and Press thus argue that traditional realist variables of power and interest explain crisis behavior and crisis outcomes far more convincingly than expectations derived by observing past actions do. Tang takes this argument a step further, claiming that reputation for resolve cannot form because of the international system's anarchic nature. ${ }^{9}$ As time has passed, even some game theorists have come to accept the findings of Mercer and especially Press as indicating that, despite the predictions of game theoretic models, past action is of little importance in subsequent interactions. ${ }^{10}$

Nor does the existing statistical literature provide clear evidence of reputation for resolve. Surprisingly few quantitative studies have directly examined the effects of reputation for resolve, and the existing literature has a number of important limitations. Studies by Huth and his co-authors provide the most prominent evidence in favor of reputation for resolve, repeatedly finding that states that adopted a conciliatory policy in crisis bargaining faced significant costs in subsequent interactions with the same actor. ${ }^{11}$ These studies, however, focus on subsets of countries and interactions, either considering extended deterrence by (primarily) great powers, or repeated interactions in the context of an enduring rivalry. Either scenario is a relatively easy case for a reputation argument because the actors and, frequently, issues under dispute are the same in the past and present interactions. Moreover, these studies frequently find an analogous negative effect of aggressive ("bullying") behavior in past crises, whereas a conventional argument about reputation for resolve would hold that willingness to court conflict would generate a positive reputation. Furthermore, Fearon argues that by conflating the use of "optimal" bargaining approaches in prior interactions with the absence of prior interactions, these studies inadvertently biased their analysis in favor of finding reputational effects. ${ }^{12}$ Elsewhere, Grieco finds that countries that failed to use force in past crises are more likely to face subsequent challenges from the same opponent, consistent with a reputational story, but also that defeat in past crises is associated with a reduced probability of a subsequent challenge by the same opponent. ${ }^{13}$ Consistent with the arguments of reputation critics, Danilovic meanwhile finds that interests in the dispute are a better predictor of extended deterrence success than reputation is. ${ }^{14}$

From a policy perspective, the work of reputation critics suggests that leaders are tragically mistaken when they commit to the use of force in the expectation of longterm benefits beyond any gains in the immediate dispute. There is no doubt that

8. Press 2005.

9. Tang 2005.

10. Slantchev $2011,54-57$.

11. See Huth 1988, 80-82; Huth and Russett 1988; Huth, Bennett, and Gelpi 1992; and Huth, Gelpi, and Bennett 1993.

12. Fearon 1994, 263.

13. Grieco 2001.

14. Danilovic 2002. 
leaders care about reputation: beyond using reputation to justify standing firm in ongoing disputes, leaders sometimes undertake costly action to restore their reputation. For example, the administration of US President Gerald R. Ford aggressively responded to the Cambodian seizure of the US container ship Mayaguez in 1975 to demonstrate resolution after Vietnam. ${ }^{15}$ More generally, Clare and Danilovic find that, at least among enduring rivals, countries that backed down in a past crisis are more likely to initiate a subsequent dispute, consistent with a reputationbuilding argument. ${ }^{16}$

However, closer examination reveals several concerns about the conclusion that reputation for resolve does not matter in international relations. First, with the partial exception of Tang, reputation critics do not have a good explanation for why leaders would so widely believe that reputation matters if in reality it does not. This point is particularly salient given the growing number of studies that have found evidence of reputations for factors other than resolve such as honesty and violence, as well as studies that demonstrate a role for reputation in alliance politics, sovereign debt, government responses to secessionist movements, and economic sanctions. ${ }^{17}$ The apparent absence of reputations for resolve in the empirical literature is thus a significant puzzle that merits further investigation.

The explanations and evidence that reputation critics provide have serious limitations. ${ }^{18}$ Press argues that power and interest are more important than reputation for resolve. But past actions matter in formal models of reputation by affecting uninformed players' estimates of opponents' interests. ${ }^{19}$ A country that backs down in a crisis is deemed to have a relatively low valuation for the political issue at stake or a relatively high subjective cost of fighting. To the extent that lessons about an actor's resolve from one crisis carry over to another, they do so in the form of statements about that actor's interests. Once this lesson is learned, however, there is no guarantee that leaders will refer back to the prior incident that led them to conclude that their opponent was resolved, instead merely observing that it has high interests in the political stake. In short, juxtaposing reputation to a realist power-and-interests story is inappropriate if estimates of interests depend in part on past actions.

Press briefly acknowledges this possibility, observing that a situation in which "a decision maker uses an adversary's history of keeping commitments to assess the adversary's interests or military power, and hence credibility," would be evidence that reputations matter. ${ }^{20}$ In practice, however, his empirical work focuses on

15. Jervis $1982,12-13$.

16. Clare and Danilovic 2010.

17. On honesty, see Sartori 2005. On violence, see Crescenzi 2007. On alliance politics, see Gibler 2008; Miller 2011; and Crescenzi et al. 2012. On debt, see Tomz 2007. On secession, see Walter 2009. On sanctions, see Peterson 2013.

18. Although we focus here on Press, we should note that even if (following Mercer) actors explain behavior in situational rather than dispositional terms, the situational explanation still might apply in other cases, a possibility that Mercer's case studies cannot rule out. Miller 2011, 36-37.

19. See Alt, Calvert, and Humes 1988; and Nalebuff 1991.

20. Press 2005, 21. 
whether or not leaders justify predictions about adversary behavior based on actions in past crises, while paying much less attention to the indirect route identified here in which past actions affect beliefs about interests, which in turn affect predictions about future behavior. Game-theoretic models of reputation formation indicate that this indirect path in fact should be the primary route by which past actions should influence current behavior, and hence by which reputations should operate.

Moreover, there is the problem, noted most prominently by Fearon, that within crises leaders are likely to focus primarily on new information, such as that gleaned from crisis negotiations or military mobilization, rather than the information that was available before the crisis. ${ }^{21}$ Past actions are by definition observable before a specific crisis. As such, we should expect their influence on opponents' perceptions to be most readily visible before the crisis as well. ${ }^{22}$ In the context of a significant crisis, leaders certainly debate the level of an opponent's resolve (that is, interests), taking into account all the available information. But by then, information gleaned from past actions-reputation-will have been folded into the general assessment of interests, alongside other pertinent sources of information such as what has been learned from the opponent's crisis behavior in the current crisis. Thus, although it would not be inconsistent with our argument for leaders to reference past action in the context of an ongoing crisis, the absence of such references is no guarantee that reputation is irrelevant. The more appropriate place to look for the effect of past actions on future expectations is at the level of general deterrence.

Consider the Argentine decision to invade the Falkland Islands in 1982. The Argentines had been pursuing the recovery of the Falklands-which they viewed as an illegitimate British colony-for decades, but the British were unwilling to force the Islanders to agree to a transfer. When the Argentine Junta decided to invade, they were confident that the British lacked the resolve to respond forcefully. ${ }^{23}$ This confidence came from apparently analogous prior conflicts, in which the British had conceded on colonial issues rather than fight. Thus,

[Argentine Foreign Minister] Costa Mendez's view was that, from [Suez in] 1956, Britain's behavior was always to deal, but not on the basis of force. Rhodesia was the most recent example. There, Britain had abandoned 600,000 British subjects. The sum of perceptions led to the conclusion that Britain would not respond with force. ${ }^{24}$

Britain thus had established a reputation for irresolution, at least over colonial issues, that contributed to the perception in Buenos Aires that the British did not care enough

21. See Fearon 1994 and 2002.

22. See also Huth 1997 , for a similar observation.

23. Most work on this conflict agrees that the junta had diversionary motives in launching the war. See Levy and Vakili 1992; and Oakes 2006. That said, the invasion likely would not have occurred had the junta not underestimated British resolve, a consequence in part of British behavior elsewhere. See Freedman and Gamba-Stonehouse 1991; and Weisiger 2013.

24. Welch 2003, 200. See also Freedman and Gamba-Stonehouse 1991, 78. 
about possessions such as the Falklands to fight for them: in short, past behavior generated a reputation for British irresolution. The discussion of past behavior occurred, however, only before the crisis that started with Argentina's surprise invasion. Although Argentine representatives repeatedly expressed their conviction that Britain did not value the islands enough to fight, a study that examined only the crisis period between the invasion and the arrival of the British taskforce would find no direct evidence that reputation mattered. ${ }^{25}$

Qualitative studies by reputation critics do not convincingly demonstrate that reputation for resolve is irrelevant, particularly at the general deterrence level. At the same time, quantitative studies that find evidence of reputation for resolve also contain findings that appear inconsistent, and other studies find weak or no evidence. Existing quantitative studies examine reputation for resolve alongside many other hypotheses, and thus do not engage in nuanced testing of this variable under different conditions and specifications. There is therefore a need for a focused quantitative study of the consequences of backing down and standing firm.

\section{Theoretical Predictions}

The literature points to two distinct and incompatible versions of the importance of reputation for resolve: reputation critics and reputation proponents. Evaluating these perspectives requires that we derive and test competing empirical implications that follow from them.

\section{Reputation Critics}

Reputation critics argue that leaders base their predictions about the opponent's behavior in subsequent interactions on immediate power and interests rather than inferring that their opponents are unresolved on the basis of having seen them back down in past disputes. If this argument is correct, then it follows that ceteris paribus countries that have done something to acquire a bad reputation will be no more likely to be targeted in subsequent interactions than any other country. Indeed, this is one clear prediction that follows consistently from the arguments of all reputation critics that can be tested statistically with readily available data. ${ }^{26}$

25. For useful overviews of the crisis period, including the absence of significant references to British past actions, see Freedman and Gamba-Stonehouse 1991; and Freedman 2005.

26. A central hypothesis for all reputation critics is that leaders will not make decisions within an ongoing crisis on the basis of their opponents' past irresolute behavior, whether because (following Mercer) that behavior was explained in situational terms and hence is irrelevant for present interactions or because (following Press) they simply focus on power and interests instead. Tests of this hypothesis must rely on leaders' contemporary statements, and hence must be conducted with case studies rather than statistically. As we argue, however, it is possible to find support for this prediction (as Press does) even in a world in which reputations for irresolution form and matter in international politics. 
H1: Countries that backed down recently will not be systematically more likely to face challenges than countries that did not back down recently.

By contrast, given differences in their underlying theories, reputation critics differ in their predictions about the value of having good reputation. For most of the critics, there is no logical difference between the purported reputation for irresolution generated by backing down in disputes and the purported reputation for resolution that is gained by demonstrating the willingness to suffer costs to attain a preferable political outcome. From this perspective, there should be no more evidence of a "good" reputation for resolve than there is for a "bad" one. ${ }^{27}$

H2a: Countries that demonstrated resolve in past conflicts will be no less likely to be challenged than countries that did not do so.

Mercer however argues that, although situational explanations for an opponent's irresolute behavior will not generalize to new disputes, resolute (and hence undesirable) behavior will be explained in dispositional terms that can travel across issues. Thus, in Mercer's theory, good reputation for resolve is possible.

$H 2 b$ (Mercer): Countries that demonstrated resolve in past conflicts will be less likely to be challenged than countries that did not do so.

\section{Reputation Proponents}

The logic of reputation, as revealed in the game-theoretical literature, indicates that reputations can be useful only in the context of repeated interactions when characteristics of the first incident are likely to also hold in the second. ${ }^{28}$ Reputation assumes a certain degree of learning: in Schelling's story, the fact that the United States fought in Korea indicated a degree of resolve to Soviet leaders that was not otherwise apparent and that allowed the Soviets to usefully predict American behavior elsewhere. Thus, any model of reputation must allow for the possibility of learning, typically by incorporating private information about one side's willingness to suffer costs to achieve desirable political ends. Most commonly, the defenders in a round of interaction knows how painful fighting is for them, whereas the attackers each initially know only that the defenders' cost of war lies somewhere along a continuum.

This uncertainty introduces a strategic dilemma for (potential) challengers. On the one hand, increased demands increase the amount that may be extorted from the defender, thus increasing utility in the event that the defender acquiesces. On

27. $\mathrm{H} 1$ and $\mathrm{H} 2 \mathrm{a}$ both predict the null hypothesis, whereas other hypotheses in this article make predictions inconsistent with the null. Because standard statistical approaches weight against rejecting the null hypothesis, this situation implicitly biases the analysis in favor of the reputation critics.

28. See Alt, Calvert, and Humes 1988; Nalebuff 1991; and Sechser 2010. 
the other hand, they cannot predict precisely the point at which the defender will move from acquiescing to ever-more stringent demands to preferring to fight. Challengers thus face a risk-return tradeoff, in which higher demands increase the probability of war, but also increase the benefits associated with peace should the defender acquiesce. ${ }^{29}$ In this context, the challengers have a strong incentive to infer as much as they can about the defender's private information so that they can make the maximum possible demand that the defender will be willing to accept.

Behavior in earlier conflicts then becomes the basis for inferring likely behavior in response to subsequent challenges. Formally, in a typical model with a continuous type space (that is, a range of possible values for the defender's resolve), the demand in the initial interaction identifies an associated cutpoint that bifurcates the type space into two related separate groups: relatively high-resolve types who reject the initial demand, and relatively low-resolve types that accept it. The response to the initial demand thus serves as a signal of resolve that can be used by actors in subsequent interactions, leading them to be more likely to make demands of actors that acquiesced and to demand more of them, relative to actors that resisted the demand.

What then are the implications of these arguments for international politics? The clearest prediction concerns general deterrence: countries that have earned a bad reputation will be more likely to be challenged, whereas those who have earned a good reputation will be less likely to face challenges. More precisely, a bad reputation leads observers to believe that they can convince the country in question to make more significant political concessions than they otherwise would have been willing to make. This inference has two effects: countries that would have initiated a crisis anyway now ask for more than they otherwise would have, and countries that would not have initiated a dispute now believe that it is worthwhile to do so. A similar relationship applies in reverse for countries with a good reputation who are less attractive targets. That is, some who would have started a dispute anyway demand less from them, and others who would have made a demand now opt not to. Although statistically testing predictions about the size of demands (especially relative to an unobservable counterfactual in which the target had behaved differently in the past) is not possible, predictions about the frequency of challenges are more straightforward to examine.

\section{H3: Countries that have backed down in the past will be more likely to be challenged subsequently; countries that have demonstrated resolve in the past will be less likely to be challenged subsequently.}

The effect of past action on subsequent behavior depends, as many scholars have noted, on the degree to which commitments are believed to be interdependent, or alternately the degree to which information learned from one dispute is believed to be relevant in other circumstances. The effects of reputation should be stronger the more 
the subsequent interaction resembles the previous one. ${ }^{30}$ There are a range of dimensions along which separate disputes might be compared, including the set of countries involved (was the potential challenger in the second dispute the same as in the first?), the issue area (does the potential second dispute concern the same type of issue as the first?), and the leaders involved (is the potential target country still governed by the same leader as in the previous interaction?). ${ }^{31}$ We thus expect greater similarity among these dimensions to be associated with a stronger effect of reputation.

H4: The effects of reputation will be stronger when the subsequent interaction more closely resembles the dispute in which the country in question earned its reputation for resolution or irresolution.

\section{Data}

Our hypotheses concern the onset and escalation of new disputes. To measure disputes, we rely on the militarized interstate dispute (MID) data set, which contains information on all known militarized incidents between countries, including threats to use force, displays of force, border violations, and actual incidents of violent conflict. In all, the MID data set identifies a total of 2,332 militarized incidents between countries from 1816 to 2001. If critics of reputation are correct that leaders believe that their reputations matter but do not take others' past actions into account when formulating their policies, and if leaders who have recently backed down sometimes seek out conflict to restore their international image, then countries that have backed down in the recent past may be more likely to be involved in disputes even though backing down had no effect on others' behavior. To address this concern, we thus rely on a directed dyad-year framework in which conflict is coded as occurring between a challenger and a target in a given year only if the challenger initiated a dispute against the target. We specifically use Maoz's directed dyadic MIDs data set, which codes dispute onset between dyads in multilateral conflicts only when the two countries in question in fact were directly involved in a dispute. ${ }^{32}$ We lag dispute onset by one year to limit concerns about potential endogeneity.

To test our predictions, we need measures of both "good" and "bad" past action, which in turn should affect observers' subsequent beliefs about countries' likely levels of resolve. To generate clear predictive effects, it is important that the logical inference drawn from past action be unambiguous. In many cases, there are multiple logical interpretations that an observer might draw from a given case. Thus, for example, a country that fights a war and loses might come to be seen as weak, which might encourage additional challenges. It also, however, might be

30. Huth 1997, Downs and Jones 2002. Tingley and Walter 2011 similarly examine circumstances in which reputation should be more or less significant.

31. For a good summary, see Press 2005, 18-20.

32. Maoz 2005. 
seen as resolved, especially if it took on a particularly strong opponent or delayed making concessions despite high military costs. In the Yom Kippur War, Egypt lost militarily, but gained politically, partly because its military fared better than in the Six Day War, but also because the decision to fight despite relative military weakness demonstrated a high degree of resolve. It is thus not obvious ex ante whether we should expect countries that fight and lose, or that achieve diplomatic successes without fighting, to be more or less likely to be challenged in the future. We argue that the inferences drawn from past action will be particularly unambiguous in two cases: when a country capitulates in a dispute without fighting, or when a country both fights and achieves victory. In the former case, while the specific inference that observers draw could concern a range of variables, including willingness to pay the costs of fighting or valuation for the stake, to the extent that the previous incident is believed to have useful lessons for subsequent interactions, the logical inference should be negative. Similarly, military victory could generate a reputation for strength or for resolve; in either case, the natural expectation is that the country would be more willing to fight if challenged on similar issues in the future.

We generate our primary measure of reputation again using the MID data set, focusing in particular on past dispute outcomes. The MID data set codes a variety of forms of dispute termination, including stalemate, compromise, yielding by one side, victory by one side, the release of prisoners or seized territory, and intervention in an ongoing interstate war. Of these outcomes, many, such as stalemate or compromise, could reflect either well or poorly on dispute participants. The two most unambiguous outcomes involve victory and yielding. In practice, the MID data set codes a dispute as ending in victory when it escalates to the use of force and one side is able to achieve its full aims, as in World War II or the Prague Spring. ${ }^{33}$ Achieving victory thus constitutes an unambiguously positive signal for a country because it entails both political success and the willingness to use force. Yielding, by contrast, typically but not always is coded in disputes that do not escalate to the use of force. In our primary measure, we code a country as acquiring a bad reputation if it yields in a dispute without resorting to the use of force (formally, if its most violent action in the dispute has a hostility level coding below 4). We also conduct a variety of robustness checks for this coding, using alternate formulations of the variable in the MID data set as well as a different version that relies on the International Crisis Behavior (ICB) data set.

Theory predicts that reputation should decline over time as the underlying variables that drive resolve shift and hence the signal from the most distant past action becomes less useful in predicting future behavior. We thus construct the variable so that it takes a value of 1 in the year immediately after the country yielded or achieved victory, declining by .1 in every subsequent year until it returns to 0

33. There are eight cases in which the MIDs data set codes a dispute as ending in victory for one side without that country escalating to the use of force. Altering the way in which these cases are handled does not materially change the statistical results. 
after a decade. In robustness checks, we generate a range of alternate variables that use different decay functions. We also generate an alternate variable that captures a country's reputation according to the following formula, where AltRep it is country $i$ 's reputation in year $t, B D_{i t}$ is the number of disputes in $t$ in which $i$ backed down (yielded), $F W_{i t}$ is the number of disputes in $t$ in which $i$ used force and won, and $O D_{i t}$ is the number of disputes in $t$ in which $i$ neither backed down nor used force and won:

$$
\text { AltRep }_{i t}=\frac{\sum_{y \in[t-10, t-1]}\left[\left(B D_{i y}-F W_{i y}\right)\left(1-\frac{t-y}{10}\right)\right]}{\sum_{y \in[t-10, t-1]}\left[\left(B D_{i y}+F W_{i y}+O D_{i y}\right)\left(1-\frac{t-y}{10}\right)\right]}
$$

AltRep $_{i t}$ takes a value between -1 and 1 , with larger values indicating that a country has backed down more frequently in recent disputes (and hence should have a bad reputation), whereas values below 0 indicate that the country should have a good reputation. Specific incidents have a bigger overall effect on the value of AltRep it when they occurred more recently and when the country has been involved in relatively few disputes in the recent past.

In addition to variables intended to capture reputation, we also include a standard list of control variables:

- CAPABILITIEs: To measure national capabilities, we rely on the standard Correlates of War National Military Capabilities data set, which starts with an index of demographic, economic, and military factors and generates a country capability score in a given year that is equal to its share of total system capabilities. The relative capabilities variable is then simply equal to the share of dyadic capabilities controlled by the stronger side in the dyad. Following Hegre, we also control for the sum of dyadic capabilities, in the expectation that increased capacity allows states to overcome the pacifying effects of distance. ${ }^{34}$

- DYADIC DEMOCRACY: The well-known democratic peace observation is that conflict is much less likely in democratic dyads than in dyads containing nondemocracies. To measure regime type, we rely on the standard Polity IV data set, following the conventional approach of subtracting a country's autocracy score from its democracy score to generate a twenty-one-point polity score. Following Russett and Oneal's weakest link operationalization, we code dyadic democracy as equal to the lower of the two democracy scores in the dyad. ${ }^{35}$

- CONTIGUITY: Countries that are close to each other are substantially more likely to come into conflict than countries that are not. ${ }^{36} \mathrm{We}$ thus control for geographic proximity, using Correlates of War data on contiguity. Our specific measure is 
a dichotomous variable that takes a value of 1 if the countries in question shared a land border or are separated by 150 miles or less of water, and 0 otherwise.

- ALLIANCE: Alliances are institutional relationships designed to manage questions of international security, and thus can be expected to influence the probability of conflict. We control for whether the two countries in a dyad were allied to each other, using the Alliance Treaty Obligations and Provisions data set data on alliances. Countries with any formal institutional relationship are coded as allied.

- MAJOR POWER STATUS: Major powers are substantially more likely to end up in conflict than are nonmajor powers, although deterrence produces a pacifying effect in relations among major powers. We thus include two dichotomous controls that capture whether one or both countries in the dyad were major powers in the year in question.

- ACTIVITY LEVEL: Our argument is that a country's behavior in past incidents influences how others act toward it. A critic might argue that the effects of reputation simply reflect a country's level of international activity: actors who are involved in many disputes have more opportunities to back down, and hence are more likely at any time to have a bad reputation that might then be seen as explaining their propensity to be involved in subsequent disputes. It is thus essential that we control for a country's past activity level, which we do using a variable that is equal to the total number of MIDs in which the potential target country was involved in the previous ten years.

- TEMPORAL DEPENDENCE: Temporal dependence in time-series cross-sectional data can produce biased standard errors and incorrect inferences. We use the approach Carter and Signorino proposed to address temporal dependence. ${ }^{37}$ To save space, we do not report results for the temporal controls.

\section{Results}

First, we examine the claim that backing down in a dispute increases the likelihood that states face subsequent challenges. Having found support for that prediction, we then turn to the generalizability of reputation, examining whether states can also acquire a good reputation for resolve, whether reputation generalizes beyond dispute participants to observers, and whether reputation applies only to the specific issue area or leader involved in the initial dispute or is more general. Except where noted, we use a probit specification, clustering standard errors by directed dyad.

\section{Reputation and Crisis Onset}

Because the reputation critics have focused in particular on the argument that there is no cost to backing down, we focus our analysis primarily on tests related to "bad" 
reputation. Table 1 presents a series of regressions that examines the basic proposition that countries that have backed down in the past are more likely to be challenged subsequently. Model 1 demonstrates that, consistent with $\mathrm{H} 3$ and inconsistent with H1, a country that backed down in the recent past is more likely to be the target of a subsequent militarized dispute. Substantively, the result indicates that a country that yielded in a dispute in the previous year is more than two and one-half times as likely to be challenged than is a country that has not yielded in the previous ten years.

Model 1, however, does not preclude the possibility that the apparent effect of reputation simply reflects the greater involvement of some countries in international politics. Some countries are involved in more international disputes, and hence are both more likely to occasionally yield and to face additional challenges. Model 2 thus inserts a control for the potential target's recent level of international activity. Consistent with the alternate explanation, the control variable is highly significant and the coefficient for the reputation variable is smaller, suggesting that at least some of the effect observed in Model 1 is spurious. That said, the reputation variable remains highly statistically and substantively significant: a country that yielded the previous year is more than twice as likely to face a challenge than is one that has not yielded in the previous ten years. Model 3 examines the role of international activity in a different manner, restricting the analysis to the subset of potential targets who had been involved in at least one militarized dispute in the previous ten years. Again, the coefficient is smaller than in Model 1, but the effect of reputation remains both statistically and substantively significant. ${ }^{38}$

The primary analysis uses a measure of reputation that codes a country as losing reputation when it yields in an MID. This is, of course, not the only possible measure of bad reputation. Model 4 presents results using a different specification based on the International Crisis Behavior data set. Specifically, a country is coded as acquiring a bad reputation in this specification if it is the coded loser of a crisis in which it did not escalate to the use of force. The observed effect is substantively indistinguishable from that reported in Models 2 and $3 .{ }^{39}$ Model 5 in turn substitutes the alternate formulation of the reputation variable $\left(\right.$ AltRep $\left._{i t}\right)$ that takes into account behavior in all recent MIDs; again results are quite comparable. ${ }^{40}$

38. Indeed, the reputation variable remains both statistically and substantively significant for a range of robustness checks, including any combination of controlling for the target's recent activity level, restricting the analysis to politically relevant dyads, and restricting the analysis to the set of countries involved in at least one dispute in the previous ten years. Results are also robust to controlling for or omitting prominent historical periods (for example, the interwar period or the Cold War) and to restricting the dependent variable to fatal MIDs.

39. In additional robustness checks, we coded countries as developing a bad reputation by yielding in an MID (with or without the use of force), by losing a crisis (again while potentially using force), or by losing an MID. Although the effect is sometimes weaker (as we would expect given the less clear signal of irresolution acquired in mixed cases in which a country both fights and loses), reputation based on past action consistently remains a robust and important predictor of subsequent challenges.

40. We do not use AltRep $i t$ as the primary variable in our analysis because doing so would significantly complicate the analysis in Table 2, where it is useful to be able to focus on reputation in interactions with particular actors or on particular issues. 
TABLE 1. Backing down and subsequent MID initiation

\begin{tabular}{|c|c|c|c|c|c|c|}
\hline & $\begin{array}{l}\text { (1) } \\
\text { Bad reputation }\end{array}$ & $\begin{array}{l}\text { (2) } \\
\text { Bad reputation }\end{array}$ & $\begin{array}{c}\text { (3) } \\
\text { Recent MIDs only }\end{array}$ & $\begin{array}{l}\text { (4) } \\
\text { ICB reputation }\end{array}$ & $\begin{array}{c}(5) \\
\text { AltRep }_{i t}\end{array}$ & $\begin{array}{c}\text { (6) } \\
\text { Fixed effects }\end{array}$ \\
\hline BAD REPUTATION & $\begin{array}{c}0.26 * * \\
(0.053)\end{array}$ & $\begin{array}{c}0.20 * * \\
(0.056)\end{array}$ & $\begin{array}{c}0.17 * * \\
(0.052)\end{array}$ & $\begin{array}{c}0.20 * * \\
(0.047)\end{array}$ & $\begin{array}{c}0.23 * * \\
(0.051)\end{array}$ & $\begin{array}{c}0.29 * * \\
(0.092)\end{array}$ \\
\hline CAPABILITY RATIO & $\begin{array}{c}-0.54 * * \\
(0.084)\end{array}$ & $\begin{array}{c}-0.57 * * \\
(0.084)\end{array}$ & $\begin{array}{c}-0.51 * * \\
(0.090)\end{array}$ & $\begin{array}{c}-0.59 * * \\
(0.086)\end{array}$ & $\begin{array}{c}-0.58 * * \\
(0.084)\end{array}$ & $\begin{array}{c}-0.49 \\
(0.34)\end{array}$ \\
\hline CAPABILITY SUM & $\begin{array}{l}3.08^{* *} \\
(0.21)\end{array}$ & $\begin{array}{l}2.82 * * \\
(0.22)\end{array}$ & $\begin{array}{l}3.03 * * \\
(0.21)\end{array}$ & $\begin{array}{l}2.83 * * \\
(0.22)\end{array}$ & $\begin{array}{l}2.84 * * \\
(0.22)\end{array}$ & $\begin{array}{l}2.48^{* *} \\
(0.55)\end{array}$ \\
\hline DEMOCRACY (low) & $\begin{array}{c}-0.0074 * * \\
(0.0020)\end{array}$ & $\begin{array}{c}-0.0067 * * \\
(0.0019)\end{array}$ & $\begin{array}{l}-0.0084 * * \\
(0.0021)\end{array}$ & $\begin{array}{l}-0.0062 * * \\
(0.0019)\end{array}$ & $\begin{array}{l}-0.0061 * * \\
(0.0019)\end{array}$ & $\begin{array}{c}-0.020 * * \\
(0.0056)\end{array}$ \\
\hline ALLIANCE & $\begin{array}{l}0.093 * * \\
(0.032)\end{array}$ & $\begin{array}{c}0.080 * \\
(0.032)\end{array}$ & $\begin{array}{l}0.094 * * \\
(0.033)\end{array}$ & $\begin{array}{c}0.069 * \\
(0.032)\end{array}$ & $\begin{array}{c}0.077 * \\
(0.032)\end{array}$ & $\begin{array}{c}-0.090 \\
(0.063)\end{array}$ \\
\hline CONTIGUITY & $\begin{array}{l}1.12 * * \\
(0.036)\end{array}$ & $\begin{array}{l}1.12 * * \\
(0.035)\end{array}$ & $\begin{array}{l}1.10^{* *} \\
(0.037)\end{array}$ & $\begin{array}{l}1.13^{* *} \\
(0.035)\end{array}$ & $\begin{array}{l}1.12 * * \\
(0.035)\end{array}$ & $\begin{array}{l}0.76^{* *} \\
(0.17)\end{array}$ \\
\hline BOTH MAJOR POWERS & $\begin{array}{c}-0.24 * \\
(0.11)\end{array}$ & $\begin{array}{c}-0.22^{*} \\
(0.11)\end{array}$ & $\begin{array}{c}-0.23^{*} \\
(0.11)\end{array}$ & $\begin{array}{c}-0.22 * \\
(0.11)\end{array}$ & $\begin{array}{r}-0.20^{\dagger} \\
(0.11)\end{array}$ & $\begin{array}{c}0.060 \\
(0.16)\end{array}$ \\
\hline ONE MAJOR POWER & $\begin{array}{c}0.28 * * \\
(0.041)\end{array}$ & $\begin{array}{c}0.26^{* *} \\
(0.041)\end{array}$ & $\begin{array}{c}0.26^{* *} \\
(0.041)\end{array}$ & $\begin{array}{l}0.27 * * \\
(0.041)\end{array}$ & $\begin{array}{r}0.26 * * \\
(0.041)\end{array}$ & $\begin{array}{l}0.68 * * \\
(0.12)\end{array}$ \\
\hline ACTIVITY LEVEL & & $\begin{array}{l}0.0098^{* *} \\
(0.0011)\end{array}$ & & $\begin{array}{l}0.0091 * * \\
(0.0011)\end{array}$ & $\begin{array}{l}0.011^{* *} \\
(0.0011)\end{array}$ & $\begin{array}{l}0.023 * * \\
(0.0025)\end{array}$ \\
\hline Constant & $\begin{array}{c}-2.51 * * \\
(0.074)\end{array}$ & $\begin{array}{c}-2.52 * * \\
(0.074)\end{array}$ & $\begin{array}{c}-2.40 * * \\
(0.080)\end{array}$ & $\begin{array}{c}-2.50^{* * *} \\
(0.076)\end{array}$ & $\begin{array}{l}-2.51 * * \\
(0.075)\end{array}$ & \\
\hline Observations & $1,187,663$ & $1,187,663$ & 840,670 & $1,187,663$ & $1,187,663$ & 72,758 \\
\hline
\end{tabular}

Note: Standard errors in parentheses are clustered by dyad except in Model $6 .{ }^{\dagger} p<0.01 ; * p<0.05 ; * * p<0.1$. 
All of these regressions make use of pooled time-series cross-sectional data, an approach that, although standard in the international relations conflict literature, has been criticized for neglecting the importance of unobserved differences across dyads. ${ }^{41}$ Model 6 thus presents results using a logit specification with dyad fixed effects. In any dyad in which no conflict occurs, the absence of conflict is ascribed to the dyad fixed effect and all relevant observations are dropped from the analysis, substantially limiting sample size. Nonetheless, reputation based on past yielding remains a significant predictor of subsequent challenges.

Control variables in Table 1, and in subsequent analyses, perform as would be expected from findings in past work. More unequal dyads are less likely to experience conflict (albeit at a statistically insignificant level in Model 6), whereas dyads that are stronger overall experience more. Consistent with past findings, alliances are typically associated with an increase in conflict onset. More contiguous dyads are similarly consistently more likely to experience conflict, whereas increased levels of dyadic democracy are associated with less conflict. Finally, as predicted, the presence of a major power in a dyad is associated with an increased probability of conflict, although this effect is offset somewhat in jointly major power dyads.

Figure 1 graphs marginal effects for substantive variables in Model 2 of Table 1, in every case holding other variables at their medians. ${ }^{42}$ Graphs are on a common axis to facilitate comparison across variables; we omit contiguity, whose substantive effect is sufficiently larger than that of other variables that a common comparison is impractical. A country that backed down the previous year is more than twice as likely to be targeted than a country that has not backed down in the previous ten years. This effect, though smaller than that for many traditionally realist variables, is slightly larger than that associated with a move from a dyad in which one country is fully autocratic to a jointly fully democratic one.

Including a range of control variables and across a number of robustness checks, therefore, there is a consistent observation that countries that yield in disputes with other countries are more likely to face a subsequent challenge than countries that do not. This finding, our most important, suggests that there is good reason for leaders to fear adverse consequences associated with backing down in disputes.

\section{The Generalizability of Reputation}

Table 2 presents results that examine how general the effects of past action are. Model 1 shifts the focus from bad reputation to good reputation, examining the proposition that countries that have fought and won in a past dispute generate a reputation for resolution that makes them less attractive targets. Consistent with $\mathrm{H} 3$, states that 
demonstrated resolve in the past are less likely to be challenged ${ }^{43}$ Holding control variables at medians, a country that has not fought to a victory in the previous ten years is 50 percent more likely to be challenged than is a country that achieved a military victory the previous year. This result holds for a variety of robustness checks, analogous to those we presented earlier. ${ }^{44}$
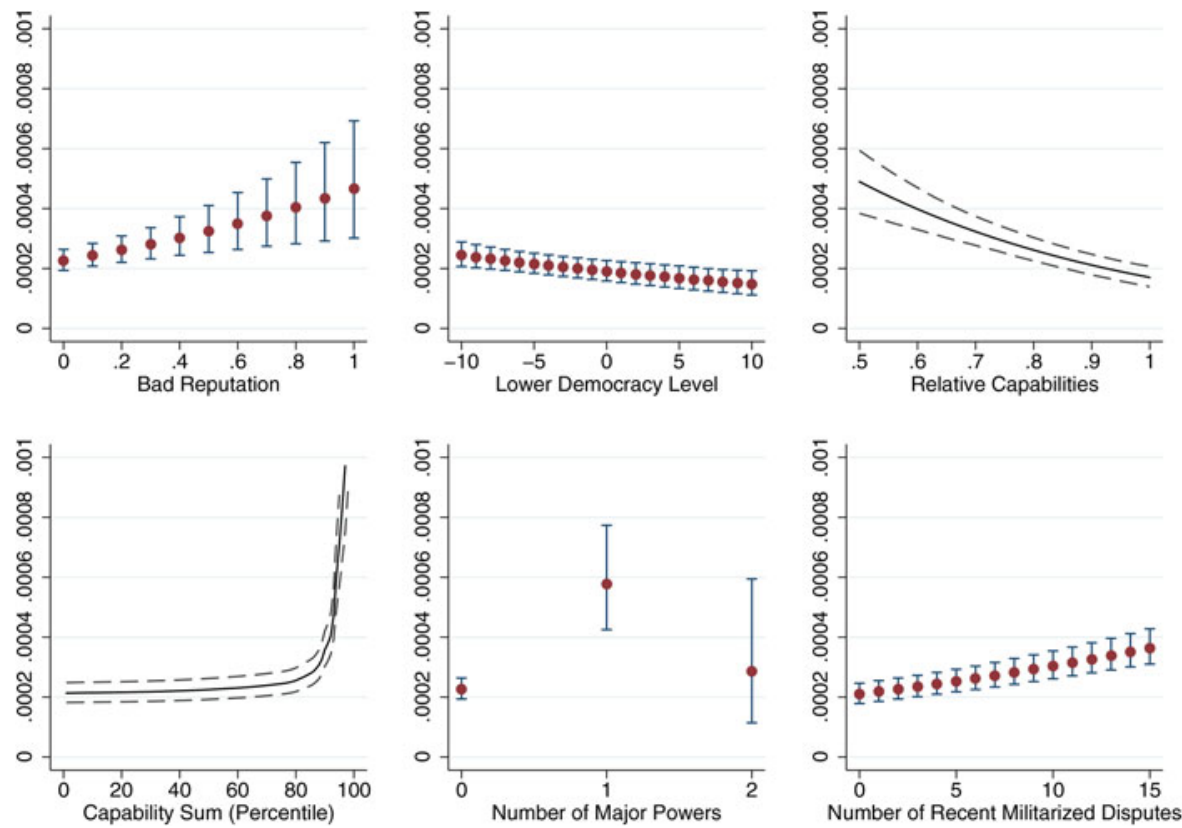

FIGURE 1. Predicted effects of explanatory variables (Table 1, Model 2)

The remaining models in Table 2 focus on the degree to which reputations gained in interactions over a particular type of issue or involving a particular actor generalize. Reputation critics have made a convincing case that reputation does not generalize to the degree that early scholars such as Schelling implied, but we argue that the opposite position-that reputation is extremely context-bound-is also inappropriate. As H4 states, we expect the effect of reputation to be stronger when the actors or issues involved are more similar to the previous dispute in which the country gained its

43. This finding is also consistent with Mercer's argument that states can gain a good (but not a bad) reputation for resolve, but it is inconsistent with the arguments of other reputation critics.

44. Without a control for the potential target's activity level, the good reputation variable is statistically insignificant and substantially quite close to 0 . This result is unsurprising: whereas for bad reputation we must be concerned that failure to control for activity level will produce an artificial positive result, the effect of activity level cuts against the prediction for a good reputation, with the result that failure to control for a country's level of international involvement may obscure a real relationship. 
TABLE 2. Testing the generalizability of reputation

\begin{tabular}{|c|c|c|c|c|}
\hline & Good reputation & $\begin{array}{c}(2) \\
\text { Observers }\end{array}$ & $\begin{array}{c}(3) \\
\text { Territory }\end{array}$ & $\begin{array}{c}(4) \\
\text { Leaders }\end{array}$ \\
\hline GOOD REPUTATION & $\begin{array}{r}-0.097 * \\
(0.048)\end{array}$ & & & \\
\hline BAD REPUTATION & & $\begin{array}{l}0.13^{*} \\
(0.056)\end{array}$ & & \\
\hline BAD REPUTATION (territory) & & & $\begin{array}{l}0.75^{* *} \\
(0.17)\end{array}$ & \\
\hline BAD REPUTATION (nonterritory) & & & $\begin{array}{l}0.17^{\dagger} \\
(0.092)\end{array}$ & \\
\hline BAD REPUTATION (same leader) & & & & $\begin{array}{c}0.24 * * \\
(0.063)\end{array}$ \\
\hline BAD REPUTATION (new leader) & & & & $\begin{array}{c}0.21 * \\
(0.085)\end{array}$ \\
\hline ACTIVITY LEVEL & $\begin{array}{c}0.011 * * \\
(0.0011)\end{array}$ & $\begin{array}{l}0.0099 * * \\
(0.0011)\end{array}$ & $\begin{array}{l}0.0096 * * \\
(0.0020)\end{array}$ & $\begin{array}{l}0.0070^{* *} \\
(0.0013)\end{array}$ \\
\hline CAPABILITY RATIO & $\begin{array}{r}-0.59 * * \\
(.085)\end{array}$ & $\begin{array}{c}-0.58 * * \\
(0.085)\end{array}$ & $\begin{array}{c}-0.74 * * \\
(0.14)\end{array}$ & $\begin{array}{c}-0.51 * * \\
(0.097)\end{array}$ \\
\hline CAPABILITY SUM & $\begin{array}{l}2.87 * * \\
(0.22)\end{array}$ & $\begin{array}{l}2.78 * * \\
(0.22)\end{array}$ & $\begin{array}{l}1.42 * * \\
(0.41)\end{array}$ & $\begin{array}{l}3.09 * * \\
(0.25)\end{array}$ \\
\hline DEMOCRACY (low) & $\begin{array}{c}-0.0062 * * \\
(0.0019)\end{array}$ & $\begin{array}{c}-0.0065^{* *} \\
(0.0020)\end{array}$ & $\begin{array}{c}-0.0029 \\
(0.0032)\end{array}$ & $\begin{array}{c}-0.0082 * * \\
(0.0023)\end{array}$ \\
\hline ALLIANCE & $\begin{array}{c}0.075^{*} \\
(0.032)\end{array}$ & $\begin{array}{l}0.087 * * \\
(0.032)\end{array}$ & $\begin{array}{c}0.021 \\
(0.049)\end{array}$ & $\begin{array}{l}0.091 * * \\
(0.034)\end{array}$ \\
\hline CONTIGUITY & $\begin{array}{l}1.12 * * \\
(0.035)\end{array}$ & $\begin{array}{l}1.11^{* *} \\
(0.035)\end{array}$ & $\begin{array}{l}1.33^{* *} \\
(0.059)\end{array}$ & $\begin{array}{c}1.17 * * \\
(0.036)\end{array}$ \\
\hline BOTH MAJOR POWERS & $\begin{array}{c}-0.21 * \\
(0.11)\end{array}$ & $\begin{array}{c}-0.20^{\dagger} \\
(0.11)\end{array}$ & $\begin{array}{l}-0.15 \\
(0.12)\end{array}$ & $\begin{array}{c}-0.21^{\dagger} \\
(0.11)\end{array}$ \\
\hline ONE MAJOR POWER & $\begin{array}{c}0.27 * * \\
(0.041)\end{array}$ & $\begin{array}{c}0.26^{* *} \\
(0.041)\end{array}$ & $\begin{array}{c}0.18^{*} \\
(0.072)\end{array}$ & $\begin{array}{c}0.28 * * \\
(0.043)\end{array}$ \\
\hline Constant & $\begin{array}{c}-2.50^{* *} \\
(0.075)\end{array}$ & $\begin{array}{r}-2.53 * * \\
(0.074)\end{array}$ & $\begin{array}{c}-2.77^{* *} \\
(0.12)\end{array}$ & $\begin{array}{c}-2.57^{* *} \\
(0.082)\end{array}$ \\
\hline Observations & $1,187,663$ & $1,187,663$ & $1,187,663$ & $1,021,833$ \\
\hline
\end{tabular}

Notes: Standard errors in parentheses are clustered by dyad. ${ }^{\dagger} p<0.01 ;{ }^{*} p<0.05 ; * * p<0.1$. 
reputation. We also expect that reputation's effects will be observable outside the immediate context of the prior dispute.

One question is whether reputations exist only dyadically, or whether potential challengers make decisions about whether or not to initiate a dispute based on incidents they are not a party to. If the effects observed in Table 1 turn out to be driven entirely by further challenges by the country to whom one acquiesced, then that implies significant limits to the generalizability of reputation. To examine this possibility, in Model 2 we simply drop observations containing the potential challenger against whom the actor in question backed down. Any positive effect of past action in this case thus reflects the behavior of previously uninvolved observers. Backing down is still associated with an increased probability of being challenged, although the effect is substantively weaker, with the change in the probability of a challenge dropping from above 100 percent to about 60 percent. This result implies that the inferences drawn from past action are stronger for countries involved in the previous disagreements, but that observers also draw lessons that affect their policy decisions. ${ }^{45}$

Model 3 extends the analysis by focusing on a specific issue, namely territorial disagreements. We code an MID as territorial if any participant has territorial aims (as captured in the MID revision type variables), and code countries as acquiring a bad territorial reputation only if they back down in a territorial MID. We then examine the effect of backing down on the onset of new territorial MIDs, setting aside cases in which disputes did not relate to territory. To provide a comparison, we also include a variable that captures recent yielding in nonterritorial disputes. Consistent with expectations, backing down in a territorial dispute is associated with a dramatic increase in the probability of a new territorial challenge. A country that backed down in a territorial dispute the previous year is more than fifteen times more likely to face a new territorial challenge than one that had not backed down in the previous ten years. However, bad reputations in nonterritorial disputes do not have the same effect on the onset of new territorial disputes-although still positive and not far from conventional statistical significance $(p=0.067)$, the relevant variable is statistically insignificant and substantively far smaller. ${ }^{46}$ This result suggests, consistent with $\mathrm{H} 4$, that the generalizability of reputation has its limits. ${ }^{47}$

45. The analogous analysis for good reputation is more complicated because there are two crosscutting effects: on the one hand, the country defeated in the prior interaction receives a strong signal of its opponent's willingness and ability to fight effectively against it, but on the other hand it is almost guaranteed to have a grievance against the country with a good reputation, whereas observers may have no disagreement. In the event, dropping dyads involving the previously defeated opponent from the analysis reveals a slightly stronger effect than was seen with all observations included $(\beta=-0.14, p<0.01)$.

46. The difference between the coefficients for the territorial and nonterritorial reputation variables is statistically significant. Results for each variable are unchanged in regressions in which the other reputation variable is omitted.

47. An analysis of the determinants of regime-related disputes reaches quite similar results. The finding does not hold for MIDs related to policy issues, however, possibly because of the wider diversity of disputes that are coded as related to policy. 
Finally, Model 4 shifts the focus from states to specific leaders. The unit of analysis here is the leader-year, with leaders identified on the basis of the Archigos data set. We then generate two reputation variables: one that corresponds to the value for the bad reputation variable when the leader who backed down is still in power, and one corresponding to the value for the bad reputation variable in cases where the leader who backed down has left power. If reputation applied only to the leader in power at the time the country backed down, we would expect the results for the first variable to be stronger than those for the second. In the event, however, the two variables are statistically indistinguishable, suggesting that leadership turnover does not produce a clean reputational slate.

\section{Conclusion}

Our findings provide strong evidence that reputation for resolve matters. Although studies by reputation critics are correct to argue that realist variables such as power and interests play an important role in states' behavior during crises, past actions have significant consequences. Countries that have backed down are substantially more likely to face subsequent challenges. We argue that the discrepancy between our results and those advanced by reputation critics may stem from their focus on crisis decision making, where information gleaned from past action will already have been incorporated into broader estimates of interests and hence is less likely to be referenced directly, as well as from their failure to recognize that reputation acts through estimates of an opponent's interests.

That said, our results do not provide unequivocal support in favor of the strong version of reputation associated with Schelling. Rather, we observe that the effects of past actions remain, but are weaker, when the subsequent interaction less closely resembles the dispute in which the country in question earned its reputation. Thus we find that past actions have a less substantive effect on the probability of a new dispute when the inferences are drawn by observers who were not involved in the previous dispute. We further find that lessons from territorial disputes are much more strongly associated with subsequent territorial challenges than are lessons from nonterritorial disputes. However, we find that reputation for resolve is not leader-specific, indicating that leader turnover in a country with a bad reputation should not significantly lower the probability that such a country will be challenged again.

Important questions about reputation remain. Reputation for resolve exists and is fairly general, but that leaves unanswered questions about the generality of reputation for other traits like honesty and reliability. Separately, although we find little change in reputation after leadership turnover, further research would be needed to definitively establish the degree to which reputations affix to leaders or to states. It is not implausible that both the generality of reputation and the degree to which inferences are drawn about specific leaders or about states in general would vary by regime type or over time. 
Our results confirm what leaders already intuitively suspect: reputation for resolve is worth having in international politics. Although backing down is not always the wrong thing to do, leaders who contemplate doing so should be aware of the associated costs.

\section{Supplementary Material}

Supplementary material for this article is available at http://thedata.harvard.edu/dvn/ $\mathrm{dv} /$ weisiger.

\section{References}

Alt, James E., Randall L. Calvert, and Brian D. Humes. 1988. Reputation and Hegemonic Stability: A Game-Theoretic Analysis. American Political Science Review 82 (2):445-66.

Bremer, Stuart A. 1992. Dangerous Dyads: Conditions Affecting the Likelihood of Interstate War, 18161965. Journal of Conflict Resolution 36 (2):309-41.

Carter, David B., and Curtis S. Signorino. 2010. Back to the Future: Modeling Time Dependence in Binary Data. Political Analysis 18 (3):271-92.

Clare, Joe, and Vesna Danilovic. 2010. Multiple Audiences and Reputation Building in International Disputes. Journal of Conflict Resolution 54 (6):860-82.

Crescenzi, Marc J.C. 2007. Reputation and Interstate Conflict. American Journal of Political Science $51(2): 382-96$.

Crescenzi, Marc J.C., Jacob D. Kathman, Katja B. Kleinberg, and Reed M. Wood. 2012. Reliability, Reputation, and Alliance Formation. International Studies Quarterly 56 (2):259-74.

Danilovic, Vesna. 2002. When the Stakes Are High: Deterrence and Conflict Among Major Powers. Ann Arbor: University of Michigan Press.

Downs, George W., and Michael A. Jones. 2002. Reputation, Compliance, and International Law. Journal of Legal Studies 31 (1):S95-S114.

Fearon, James D. 1994. Signaling Versus the Balance of Power and Interests: An Empirical Test of a Crisis Bargaining Model. Journal of Conflict Resolution 38 (2):236-69.

- 2002. Selection Effects and Deterrence. International Interactions 28 (1):5-29.

Freedman, Lawrence. 2005. The Official History of the Falklands Campaign. London: Routledge.

Freedman, Lawrence, and Virginia Gamba-Stonehouse. 1991. Signals of War: The Falklands Conflict of 1982. Princeton, NJ: Princeton University Press.

Gibler, Douglas M. 2008. The Cost of Reneging: Reputation and Alliance Formation. Journal of Conflict Resolution 52 (3):425-54.

Green, Donald P., Soo Yeon Kim, and David H. Yoon. 2001. Dirty Pool. International Organization 55 (2):441-68.

Grieco, Joseph M. 2001. Repetitive Military Challenges and Recurrent International Conflicts, 1918-1994. International Studies Quarterly 45 (2):295-316.

Hegre, Håvard. 2008. Gravitating Toward War: Preponderance May Pacify, but Power Kills. Journal of Conflict Resolution 52 (4):566-89.

Hopf, Ted. 1994. Peripheral Visions: Deterrence Theory and American Foreign Policy in the Third World, 1965-1990. Ann Arbor: University of Michigan Press.

Huth, Paul K. 1988. Extended Deterrence and the Outbreak of War. American Political Science Review $82(2): 423-43$. 
1997. Reputations and Deterrence: A Theoretical and Empirical Assessment. Security Studies 7 (1):72-99.

Huth, Paul K., and Bruce M. Russett. 1988. Deterrence Failure and Crisis Escalation. International Studies Quarterly 32 (1):29-45.

Huth, Paul K., D. Scott Bennett, and Christopher F. Gelpi. 1992. Systemic Uncertainty, Risk-Propensity, and International Conflict Among the Great Powers. Journal of Conflict Resolution 36 (3):478-517.

Huth, Paul K., Christopher F. Gelpi, and D. Scott Bennett. 1993. The Escalation of Great Power Militarized Disputes: Testing Rational Deterrence Theory and Structural Realism. American Political Science Review 87 (3):609-23.

Jervis, Robert. 1979. Deterrence Theory Revisited. World Politics 31 (2):289-324. . 1982. Deterrence and Perception. International Security 7 (3):3-30.

Lebow, Richard N. 1981. Between Peace and War: The Nature of International Crisis. Baltimore, MD: Johns Hopkins University Press.

Levy, Jack S., and Lily I. Vakili. 1992. Diversionary Action by Authoritarian Regimes: Argentina in the Falklands/Malvinas Case. In The Internationalization of Communal Strife, edited by Manus I. Midlarsky, 118-46. London: Routledge.

Maoz, Zeev. 2005. Dyadic Militarized Interstate Dispute Dataset Version 2.0. Available at <http://vanity. dss.ucdavis.edu/ maoz/dyadmid.html>. Accessed 15 September 2012.

Mercer, Jonathan. 1996. Reputation and International Politics. Ithaca, NY: Cornell University Press.

Miller, Gregory D. 2011. The Shadow of the Past: Reputation and Military Alliances Before the First World War. Ithaca, NY: Cornell University Press.

Nalebuff, Barry. 1991. Rational Deterrence in an Imperfect World. World Politics 43 (3):313-35.

Oakes, Amy. 2006. Diversionary War and Argentina's Invasion of the Falklands Islands. Security Studies 15 (3):431-63.

Orme, John D. 1992. Deterrence, Reputation, and Cold-War Cycles. Basingstoke, UK: Macmillan.

Peterson, Timothy M. 2013. Sending a Message: The Reputation Effect of US Sanction Threat Behavior. International Studies Quarterly 57 (4):672-82.

Powell, Robert. 1999. In the Shadow of Power: States and Strategies in International Relations. Princeton, NJ: Princeton University Press.

Press, Daryl G. 2005. Calculating Credibility: How Leaders Assess Military Threats. Ithaca, NY: Cornell University Press.

Russett, Bruce M., and John R. Oneal. 2001. Triangulating Peace: Democracy, Interdependence, and International Organizations. New York: Norton.

Sartori, Anne E. 2005. Deterrence by Diplomacy. Princeton, NJ: Princeton University Press.

Schelling, Thomas C. 1960. The Strategy of Conflict. Cambridge, MA: Harvard University Press.

-1966. Arms and Influence. New Haven, CT: Yale University Press.

Sechser, Todd. 2010. Goliath's Curse: Coercive Threats and Asymmetric Power. International Organization 64 (4):627-60.

Slantchev, Branislav L. 2011. Military Threats: The Costs of Coercion and the Price of Peace. New York: Cambridge University Press.

Snyder, Glenn H., and Paul Diesing. 1977. Conflict Among Nations: Bargaining, Decision Making, and System Structure in International Crises. Princeton, NJ: Princeton University Press.

Tang, Shiping. 2005. Reputation, Cult of Reputation, and International Conflict. Security Studies 14 (1): 34-62.

Tingley, Dustin, and Barbara F. Walter. 2011. The Effect of Repeated Play on Reputation Building: An Experimental Approach. International Organization 65 (2):343-65.

Tomz, Michael. 2007. Domestic Audience Costs in International Relations: An Experimental Approach. International Organization 61 (4):821-40.

Treisman, Daniel. 2004. Rational Appeasement. International Organization 58 (2):345-73.

Walter, Barbara F. 2009. Reputation and Civil War: Why Separatist Conflicts Are So Violent. New York: Cambridge University Press. 
Weisiger, Alex. 2013. Logics of War: Explanations for Limited and Unlimited Conflicts. Ithaca, NY: Cornell University Press.

Welch, David A. 2003. Culture and Emotion as Obstacles to Good Judgment: The Case of Argentina's Invasion of the Falklands/Malvinas. In Good Judgment in Foreign Policy: Theory and Application, edited by Stanley A. Renshon and Deborah W. Larsen, 191-215. Lanham, MA: Rowman and Littlefield. Wolford, Scott. 2007. The Turnover Trap: New Leaders, Reputation, and International Conflict. American Journal of Political Science 51 (4):772-88. 